\title{
Development of the Algorithm for Definition of Residual Service Life by a Comprehensive Diagnosis of the Electromechanical Drive
}

\author{
Pavel Stepanov ${ }^{1 *}$, Stanislav Lagutkin ${ }^{2}$ and Yury Nikitin ${ }^{3}$ \\ 'Novouralsk Technological Institute (Branch of National Research Nuclear University "MEPhl"), Department of Control Automation, Novouralsk, Russia \\ ${ }^{2}$ Novouralsk Technological Institute (Branch of National Research Nuclear University "MEPhl"), Department of Mechanical Engineering, Novouralsk, \\ Russi \\ ${ }^{3}$ Kalashnikov Izhevsk State Technical University, "Mechatronic Systems" Department, Izhevsk, Russia
}

\begin{abstract}
The algorithm for determining the residual service life of the stand, which consists of an asynchronous motor, clutch and worm gear, is developed. As a comprehensive approach the analysis of mechanical and electrical drive diagnostic parameters is considered. The change in vibration speed and spectral coefficients of the wavelet analysis of the stator electric current is investigated under load in the presence and absence of defects. The equation is received to determine the residual service life.
\end{abstract}

Keywords: Diagnostics, electromechanical drive, worm gear, vibration, electric current, wavelet analysis.

\section{Introduction}

With increasing of automation in modern production requirements for reliability are rising up. To avoid emergency stop of automated processing equipment, it is necessary to carry out the diagnosis and to predict the unit accidents, which may occur during operation. Thus, an equipment diagnosis is becoming the most promising and fastest growing aspect of modern production and the definition of residual life - is the basis for the most cost-effective functioning of components and machines.

In [1-12] questions of diagnostics for electric motors and processing equipment are considered. Also the attention is paid to find a residual service life by means of fuzzy logic $[1,3]$.

In [5-7] mechanical and electric diagnostic parameters for definition of technical condition of the electromechanical drive were investigated. Changes of a range of vibration speed and coefficients of wavelet-transformation of electric current of the stator are revealed at absence and existence of various defects.

\section{Experimental Section}

Experimental research was conducted at the stand consisting of the asynchronous motor, the coupling and the worm reducer. For definition of a residual service life a number of experiments was carried out. It is revealed that such kind of malfunction as lack of greasing in a gear can lead to emergence of a certain defects of 


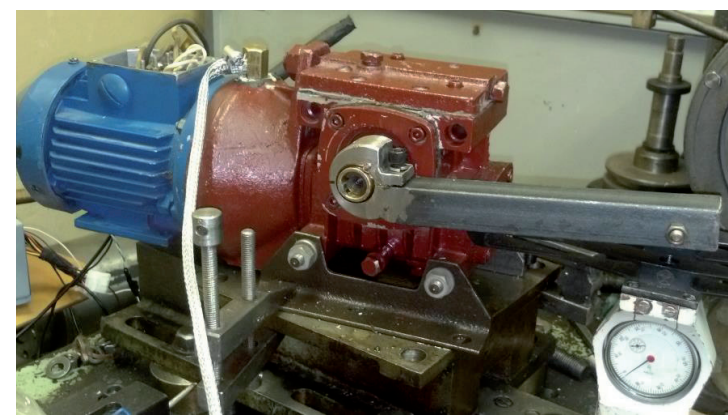

Fig. 1: The laboratory stand.

a tooth gearing. Therefore, at the laboratory stand emulation of such type of malfunction was carried out. The photo of the stand is given in fig. 1.

The vibrator inverter AP2019 (fastening on the coupling using a magnet) and current sensors LEM LA-55P (installation on 3 phases of the asynchronous motor's stator) were used.

All data were recorded in a mode with load of worm-and-wheel reduction unit $(\mathrm{M}=32 \mathrm{Nm})$.

Electric motor power $\mathrm{P}=0,18 \mathrm{~kW}$. Rotation speed $\mathrm{N}=1350 \mathrm{rpm}$. Worm gear is MU-40M-31,5-47,651-5-1C-У3. The oscillograph Tektronix TDS3014 was used to record signals and process them in MathCAD and MathLAB software.

Data collection parameters: the number of samples $N=10000$, reading data time $t=2 \mathrm{~s}$, the period $\mathrm{dt}=0.0002 \mathrm{~s}$, sampling frequency $\mathrm{u}=5000 \mathrm{~Hz}$.

As basic data parameters of the serviceable drive are received. The oscillogram of vibration acceleration and a range of vibration speed of completely serviceable electromechanical drive under loading are given in fig. 2 and 3. The general level of vibration, equal $448,31 \mathrm{~mm} / \mathrm{c}^{2}$ is recorded. The received wavelet transformation coefficients for the first phase of the stator for the serviceable drive are given in fig. 4. In the analysis Daubechies wavelets $(\mathrm{db}-8)$ were used. For the analysis of the motor current a table 1 was correspond to the coefficients of the wavelet transform bands of the spectrum of the motor current.

Further the grease was removed from a reducer and measurements were repeated in every 3 hours. The results of measurements after 24 hours of stand functioning are given in fig. 5-7. The general level of vibration, equal $1144 \mathrm{~mm} / \mathrm{s}^{2}$ is recorded. The increase in average mean-square deviation of wavelet-coefficient of d5 from 0,11 up to 0,13 is traced.
Table 1: Frequency Bands of the stator current with wavelet transform.

\begin{tabular}{|l|l|l|}
\hline Value dt (s) & Specification & \multicolumn{1}{c|}{ Sub-band (Hz) } \\
\hline 0,0002 & D1 & $2500 \ldots 5000$ \\
\hline & D2 & $1250 \ldots 2500$ \\
\hline & D3 & $625 \ldots 1250$ \\
\hline & D4 & $312,5 \ldots 625$ \\
\hline & D5 & $156,3 \ldots 312,5$ \\
\hline & D6 & $78,1 \ldots 156,3$ \\
\hline & D7 & $39 \ldots 78,1$ \\
\hline & D8 & $19,5 \ldots 39$ \\
\hline & \\
\hline
\end{tabular}

Fig. 2: The oscillogram of vibration acceleration $\left(\mathrm{mm} / \mathrm{s}^{2}\right)$ for serviceable stand.

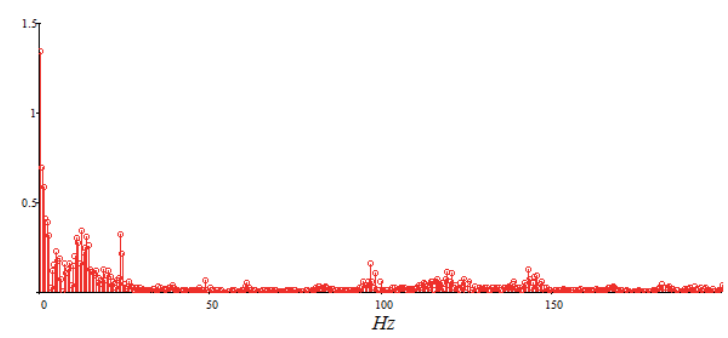

Fig. 3: The spectrum of vibration speed $(\mathrm{mm} / \mathrm{s})$ for serviceable stand.

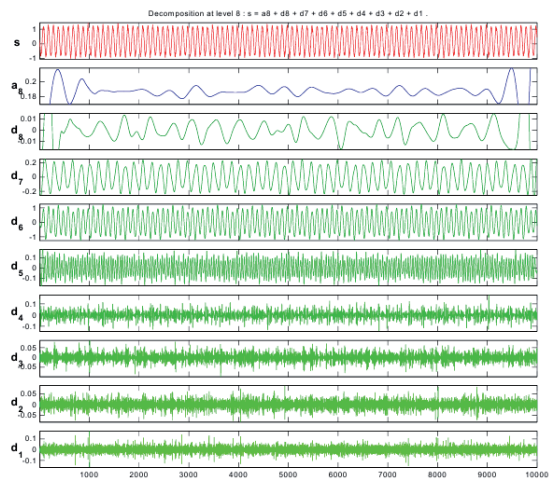

Fig. 4: The electric current of the first phase of the serviceable motor stator and its wavelet transform. 


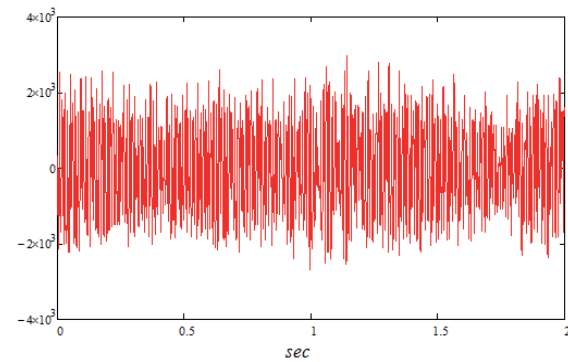

Fig. 5: The oscillogram of vibration acceleration $\left(\mathrm{mm} / \mathrm{s}^{2}\right)$ after 24 hours.

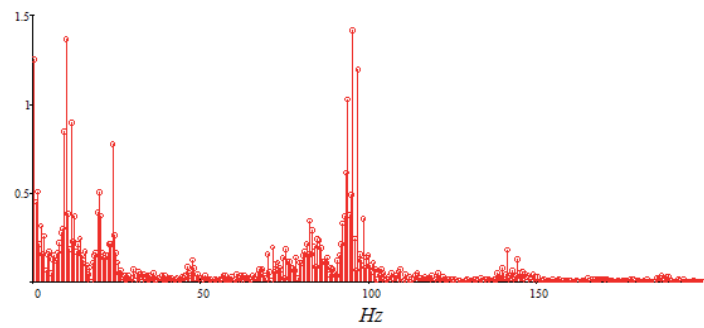

Fig. 6: The spectrum of vibration speed $(\mathrm{mm} / \mathrm{s})$ after 24 hours.

On the spectrum of vibration speed the rise of amplitude at a tooth frequency of a reducer $(90 \mathrm{~Hz})$ up to $1,5 \mathrm{~mm} / \mathrm{s}$ and also emergence of a set of side harmonicas are observed. This fact shows the obvious presence of defect of a tooth gearing.

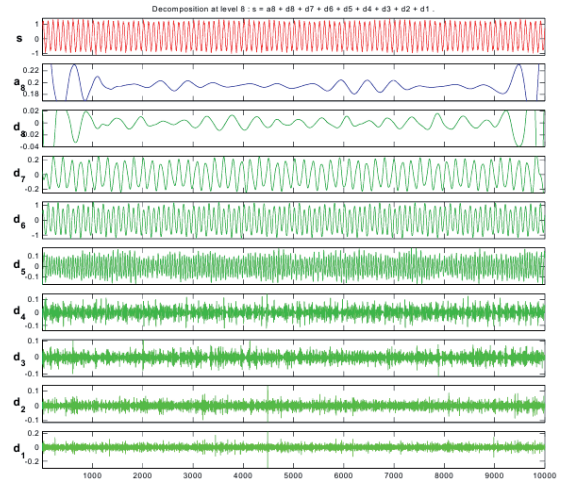

Fig. 7: The electric current of the first phase of the motor stator and its wavelet transform after 24 hours.

Further experiments for determination of the maximum value of the general level of vibration and coefficient $d_{5}$ were made (since it was more sensitive to such kind of defect). The received results: $v_{\max }=2430 \mathrm{~mm} / \mathrm{s} ; \mathrm{d}_{5 \max }=0,18$.

By linear approximation the diagram of change for the general level of vibration during an operation of the stand (the trend) in the conditions of grease lack in a reducer (fig. 8) is received.

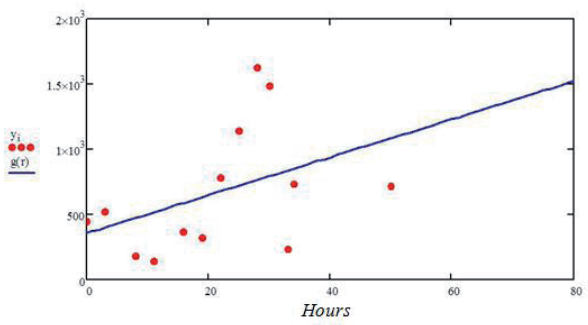

Fig. 8: The trend of vibration of the stand $\left(\mathrm{mm} / \mathrm{s}^{2}\right)$ with grease lack in a reducer within 50 hours.

The diagram of change for the wavelet-coefficient $d_{5}$ (fig. 9) is similarly received.

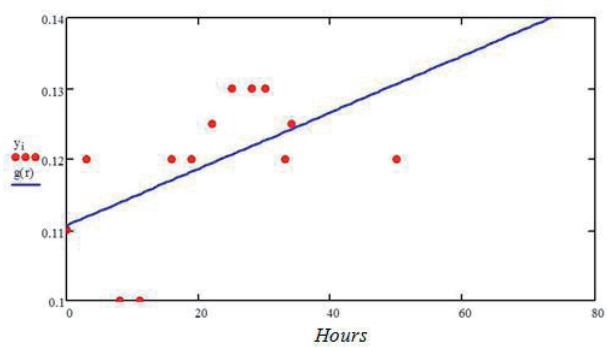

Fig. 9: The trend of wavelet-coefficient $d 5$ with grease lack in a reducer within 50 hours.

Further, the equations for approximation of experimental data were received:

$v=14,57 t+356,543$;

$d_{5}=0,0004 t+0,111$

Now, by substituting in expression (1) of maximum values $v_{\max }$ and $\mathrm{d}_{5 \mathrm{max}}$, it is possible to define a residual life for operation of the stand in the current mode (2).

$t=\frac{v-d_{5}-356,432}{14,57}$

At continuous monitoring of the equipment it is necessary to recalculate the received values and plot the graphs with a certain period. It will lead to the greatest accuracy in determination of a residual life.

At real operation of the equipment where various modes of loading take place, use of criterion of Bailey is quite possible. 


\section{Conclusions}

In this work the algorithm for definition of residual service life is developed. Mechanical and electric diagnostic parameters of the electromechanical drive were considered. It is shown that change of a spectrum of vibration speed and coefficients of the wavelet-analysis of electric current of the stator is directly connected with existence or lack of defects.

\section{Acknowledgments}

The reported study was partially supported by RFBR, research project No. 13-08-01181 a.

\section{References and Notes}

[1] Abramov, I., Nikitin, Y., Zorina, O., Božek, P., Stepanov, P., Stollmann, V. (2014). Monitoring of technical condition of motors and bearings of woodworking equipment. Acta Facultatis Xylologiae, vol. 56(2), pp. 97-104.

[2] Abramov, I., Nikitin, Yu., Abramov, A., Sosnovich, E., Božek, P., Stollmann, V. (2014). Diagnosis of rolling mill line gearmotors. Proc. of International Conference on Innovative Technologies, IN-TECH 2014. Leiria, Portugal, pp. 155-158, Sep. 10-13.

[3] Abramov, I. V., Nikitin, Yu. R., Abramov, A. I., Sosnovich, E. V., Božek, P. (2014). Control and diagnostic model of brushless DC motor. Journal of Electrical Engineering, vol. 65, no. 5, pp. 277- 282.

[4] Hammer, M., Šimková, M., Ministr, M. (2010). Artificial Intelligence in Diagnostics of Electric Machines. In Recent Advances in Mechatronics, Springer, Berlin Heidelberg, pp. 139-144.

[5] Stepanov P., Nikitin Yu. (2014). Diagnostics of Mechatronic Systems on the Basis of Neural Networks with High-Performance Data Collection. Mechatronics 2013: Recent Technological and Scientific Advances, pp. 433-440. Brno, Czech Republic, Springer Intrenational Publishing Swizerland.

[6] Stepanov P., Lagutkin S. (2014). Research of Electric and Mechanical Diagnostic Parameters of Drive Equipment. Applied Mechanics and Materials, vol. 683, pp. 177-281. Trans Tech Publications, Switzerland.

[7] Stepanov P., Lagutkin S., Božek P., Nikitin Yu. (2014). Comprehensive approach to technical conditions of electromechanical units in mechatronic systems. American Journal of Mechanical Engineering, vol. 2, No. 7, pp. 278-281.

[8] Cowan, R.S., Winer, W.O. (2013). Handbook of Technical Diagnostics: Fundamentals and Application to Structures and Systems. Machinery Diagnostics, pp. 387-410. Springer Berlin Heidelberg.

[9] Dovban', S.N., Veselov, O.V. (2012). Technical diagnostics of electromechanical systems based on the analysis of distorted output signal. Automation and Remote Control, vol. 73, Issue 11, pp. 1902-1909. November 2012.

[10] Hetmanczyk, M.P., Swider, J.A. (2014). Selected vibrational symptoms in transient states of AC drives. International Journal of Dynamics and Control, Feb. 2014. [Online] Available: http://link.springer.com/article/10.1007/s40435-0140062-0/fulltext.html [Accessed Dec. 2, 2014].

[11] Virgala, I., Frankovský, P., Kenderová, M. (2013). Friction Effect Analysis of a DC Motor. In: American Journal of Mechanical Engineering. Vol. 1, no. 1 (2013), p. 1-5. ISSN 2328-4102.

[12] Lee, Y.S., Kim, Y.W. (2007). Condition monitoring of induction motors for vertical pumps with the current and vibration signature analysis. Experimental analysis of nano and engineering materials and structures, pp. 419-420. Springer, Dordrecht.

[13] Virgala, I., Frankovský, P., Kenderova, M. (2013). Friction Effect Analysis of a DC Motor. In: American Journal of Mechanical Engineering, 1(1), 1-5.

[14] Živčak, J., Kelemenová, T., Kelemen, M., Maxim, V.: Modelbased approach to development of engineering. In: Acta Mechanica Slovaca. Roč. 17, č. 3 (2013), s. 56-62. - ISSN $1335-$ 2393

[15] Kuryło P.: The study of residual stresses in the surface layer. In: Acta Mechanica Slovaca. 2013, Vol. 17, no. 4, s. 6-15

\section{Biographical notes}

Stepanov Pavel, CSc., (1988). Actual professional or academic position (function and workplace): Senior lecturer of Novouralsk Technological Institute (Branch of National Research Nuclear University "MEPhl"), Department of Control Automation. Graduated: Department of Mechanical Engineering in Novouralsk Technological Institute (Branch of National Research Nuclear University "MEPhl"), The specialty - "Mechatronic", 2010. The author of 15 scientific papers. Professional orientation or specialisation: Diagnosis, mechatronic systems, robotics.

Lagutkin Stanislav, Dr.-Ing., (1977). Actual professional or academic position (function and workplace): Associate professor (lecturer) of Novouralsk Technological Institute (Branch of National Research Nuclear University "MEPhI"), Department of Mechanical Engineering. Graduated: Department of Mechanical Engineering in Moscow Engineering-Physical University, The specialty - "Technologies of automation of industrial productions," 1999. The most remarkable professional or academic positions or functions till now: the head of 2 research projects, the implementer of 6 research projects, the author of 29 scientific papers. Professional orientation or specialisation: Diagnosis, mechatronic systems, powder metallurgy. Membership in the most important professional or academic institutions: Technical director of "Expert TM Ltd."

Nikitin Yury, CSc, (1966).Actual professional or academic position (function and workplace): Assoc. prof. (lecturer) of Kalashnikov lzhevsk State Technical University, "Mechatronic Systems" Department. Graduated: Faculty of Instrumentation Engineering of Izhevsk Institute of mechanical engineering on the speciality of the computer designing, 1988. The most remarkable professional or academic 
positions or functions till now: head of 2 research projects, implementer of 3 research projects, author of over 150 scientific papers, member of the Scientific Committees of magazines "Management of Companies" and "Interdisciplinarity in Theory and Practice", expert of the Czech Science Foundation - Grant Agency of the Czech Republic, member of the 5 Scientific Committee of International conferences. Professional orientation or specialisation: diagnosis, mechatronic systems, robotics. Membership in the most important professional or academicinstitutions: member of Academy of Quality Problems of Russia. 